\title{
PENELITIAN
}

\section{HUBUNGAN WAKTU PENGGUNAAN SERAGAM KLINIK DENGAN PENINGKATAN JUMLAH MIKROORGANISME*}

\author{
Hanny Handiyani *, Ns. Yasephin Megapurwara **
}

\begin{abstract}
Abstrak
Pengelolaan seragam klinik perlu mendapatkan perhatian, mengingat pengelolaan seragam klinik yang tidak tepat dapat menyebabkan penyebaran infeksi nosokomial (IN). Pencegahan infeksi nosokomial dapat dilakukan melalui pengaturan penggunaan seragam klinik mahasiswa. Penelitian ini bertujuan memperoleh informasi sejauh mana hubungan waktu penggunaan seragam klinik dengan peningkatan jumlah mikroorganisme. Desain penelitian ini adalah deskriptif korelatif. Penelitian ini dilakukan selama tiga hari berturut-turut terhadap tiga sampel seragam dengan membandingkan jumlah koloni pada seragam sebelum penggunaan, penggunaan hari pertama, dan setelah penggunaan hari kedua. Berdasarkan analisis data menggunakan rumus ANOVA didapatkan data terjadi peningkatan yang bermakna terhadap jumlah koloni pada penggunaan seragam pada hari kedua dibandingkan dengan jumlah koloni sebelum penggunaan seragam ( $p$ value 0,012 ). Penelitian ini merekomendasikan perlunya peningkatan kesadaran mahasiswa dalam mengelola seragam kliniknya sebagai upaya mengontrol terjadinya infeksi nosokomial (IN) dengan cara mengganti seragam klinik setiap hari.
\end{abstract}

Kata kunci: mahasiswa, mikroorganisme, seragam klinik

\begin{abstract}
The clinical uniform management needs more attention since its' inappropriate clinical management may increase the insident of nosocomial infection. The prevention of nosocomial infection can be done by an appropriate clinical uniform management. This study aimed to measure the correlations between the lenghts of use the uniform and the increase in the number of microorganism. This study used the decriptive correlation design. This study was done three days in rows to three uniform samples by comparing the number of microorganism before it was used, after the first day of its usage and after the second day of its usage. Based on the ANOVA analysis, the study found that there is a significant increase in the number of microorganism of the second days of its usage compared with before its usage (p value 0,012). This study recommends that the students'awareness should be increase on clinical uniform management as a way to reduce the risk of nosocomial infection by changing the uniform everyday.
\end{abstract}

Key words: : clinical uniform, microorganism, students

\section{PENDAHULUAN}

Pakaian seragam digunakan oleh setiap tenaga kesehatan yang bekerja di rumah sakit (RS). Seragam juga digunakan oleh mahasiswa profesi keperawatan yang menjalankan praktik klinik di RS. Pakaian seragam perlu mendapat perhatian mengingat pengelolaan seragam klinik yang tidak tepat dapat menyebabkan penyebaran (IN) dari RS ke masyarakat. Pencegahan IN dapat dilakukan dengan berbagai cara, di antaranya melalui pengaturan penggunaan seragam klinik mahasiswa. Selama beberapa tahun, seragam perawat dinilai belum efektif dalam manfaat dan penggunaan (Dring 1987). Seragam perawat merupakan salah satu media untuk terjadinya infeksi nosokomial. Walker dan Donaldson (1993) menyatakan bahwa perlu ditingkatkan penelitian terkait dengan peningkatan efektivitas seragam perawat dalam perannya sebagai proteksi diri perawat dan meminimalkan risiko terjadinya infeksi nosokomial.

Penggunaan seragam klinik mahasiswa keperawatan sampai saat ini masih bervariasi. Kebijakan institusi pendidikan mengharuskan mahasiswa menggunakan seragam hanya saat akan praktik klinik (tidak langsung memakai seragam klinik dari rumah namun menggantinya di ruang ganti pakaian di dekat tempat praktek klinik) dan tidak menggunakan seragam tersebut sampai ke rumah. Mahasiswa juga diharapkan memiliki minimal dua stel seragam klinik agar dapat diganti 
Jurnal Keperawatan Indonesia, Volume 10, No.1, Maret 2006; 5-10

setiap hari. Berdasarkan pengamatan peneliti saat membimbing klinik keperawatan ditemukan mahasiswa menggunakan satu seragam klinik lebih dari satu hari dan menggunakannya sampai ke rumah dengan alasan waktu (tidak sempat mengganti pakaian). Salah satu penyebabnya adalah karena keterbatasan jumlah seragam yang tersedia dan keterbatasan dalam sarana dan prasarana pencucian seragam. Hal ini tentunya meningkatkan resiko terjadinya infeksi nosokomial.

Fenomena di RS menunjukkan bahwa terbatasnya pemahaman perawat akan upaya pencegahan IN membawa perawat berperilaku tidak tepat dalam mencegahnya, seperti: penggunaan seragam dinas yang sama selama beberapa hari (seragam yang telah dipakai tidak langsung dicuci melainkan digantung di lemari untuk dipakai keesokan harinya), menggunakan baju dinas di luar lingkungan rumah sakit atau pulang masih dengan seragam klinik, dan memiliki keterbatasan dalam mengelola (membersihkan) seragam dinas dengan tepat di rumah. Banyak di antara perawat dan mahasiswa yang kurang memperhatikan petunjuk pencucian pakaian seragam dinas jika dicuci di rumah.

Peneliti tertarik untuk melihat apakah penggunaan seragam yang berulang kali itu juga meningkatkan jumlah mikroorganisme yang melekat pada segaram klinik. Hal ini tentunya mendukung terjadinya infeksi nosokomial. Bila infeksi ini menyebar ke masyarakat, maka akan lebih sulit lagi untuk mengatasinya. Apalagi mikroorganisme yang resisten terhadap pengobatan pada saat ini juga semakin meningkat.

Peneliti tertarik untuk membuktikan adanya hubungan antara waktu penggunaan seragam klinik dengan peningkatan jumlah mikroorganisme. Hasil penelitian ini diharapkan dapat lebih meningkatkan kesadaran mahasiswa tentang perilaku yang dapat mencegah terjadinya infeksi nosokomial dan menggugah pengelola institusi pendidikan untuk membuat kebijakan yang tepat tentang penggunaan seragam klinik sebagai upaya mengontrol terjadinya infeksi nosokomial.

Penggunaan seragam klinik yang tidak tepat dapat menyebarkan infeksi rumah sakit ke komunitas.
Kesadaran penggunaan seragam yang tepat perlu dilandasi oleh studi klinik penggunaan seragam sehingga dapat menjawab:

a. Apakah ada peningkatan jumlah mikroorganisme pada seragam klinik yang telah digunakan mahasiswa praktik profesi keperawatan?

b. Apakah semakin lama seragam klinik digunakan akan semakin meningkatkan jumlah mikroorganisme pada seragam tersebut?

Penelitian ini bertujuan untuk memperoleh informasi sejauh mana hubungan waktu penggunaan seragam klinik dengan peningkatan jumlah mikroorganisme pada seragam klinik. Secara khusus, penelitian ini juga bertujuan agar diketahuinya waktu penggunaan seragam klinik mahasiswa keperawatan, diketahuinya jumlah koloni pada setiap hari penggunaan seragam klinik, serta diketahuinya hubungan waktu penggunaan seragam klinik dengan peningkatan jumlah mikroorganisme pada seragam klinik

Penelitian ini penting dilakukan karena keuntungan yang dihasilkannya untuk pengembangan ilmu pengetahuan terutama terkait dengan pencegahan penyebaran infeksi nosokomial. Keuntungan yang didapatkan oleh institusi pendidikan dari hasil penelitian ini adalah adanya landasan ilmiah dalam mengelola jumlah seragam klinik program profesi yang diperlukan mahasiswa terkait dengan efektivitas waktu penggunaan seragam tersebut. Untuk masyarakat, hasil penelitian ini jika diterapkan akan menurunkan insiden infeksi nosokomial di antara klien di dalam ruang rawat dan menurunkan risiko penyebaran infeksi dari rumah sakit ke lingkungan masyarakat. Untuk institusi pelayanan, hasil penelitian ini dapat diterapkan untuk pengelolaan penggunaan seragam dinas di rumah sakit. Hasil dari penelitian ini juga dapat menunjang penelitian-penelitian selanjutnya yang berhubungan dengan pengelolaan linen dan infeksi nosokomial.

\section{TINJAUAN TEORITIS}

Rumah sakit merupakan tempat yang memiliki peluang untuk menimbulkan terjadinya infeksi karena memiliki jumlah kuman terbanyak, di mana sebagian dari kuman-kuman tersebut telah resisten terhadap antibiotik. Sangat disayangkan bahwa 
ternyata terjadinya infeksi nosokomial di rumah sakit salah satunya terjadi melalui tenaga kesehatan. Hal tersebut dikenal dengan infeksi iatrogenik yaitu infeksi nosokomial yang terjadi karena prosedur diagnostik maupun pemberian pelayanan kesehatan. Salah satu contohnya adalah infeksi yang terjadi karena pemasangan kateter urin yang kurang steril. Insiden infeksi nosokomial dapat diturunkan jika perawat menggunakan kemamppuan berpikir kritis selama melaksanakan pemberian asuhan keperawatan. Perawat harus selalu memperhatikan resiko infeksi yang mengkin terjadi pada klien dan mengantisipasi serta meningkatkan pendekatan asuhan keperawatan dalam upaya menurunkan infeksi nosokomial. Salah satu upaya yang dapat dilakukan adalah melalui pengelolaan seragam secara tepat (Potter\&Perry, 2001).

Manajemen pelayanan linen di rumah sakit merupakan sub sistem dari pelayanan rumah sakit yang memiliki peran penting terutama dalam pencegahan peningkatan infeksi nosokomial yang akan berperan terhadap peningkatan status kesehatan klien. Pengelolaan seragam perawat termasuk salah satu bagian penting dari manajemen linen rumah sakit. Infeksi nosokomial dapat terjadi selama pemberian pelayanan kesehatan di rumah sakit.

Perilaku sehat tenaga kesehatan khususnya perawat sebetulnya sangat berarti dalam upaya pengontrolan infeksi nosokomial di rumah sakit. Hal ini dimulai dari kebersihan perorangan perawat dan penerapan kebiasaan yang mendukung kesehatan. Kebersihan lingkungan, teknik mencuci tangan yang benar, penerapan prinsip teknik aseptik, mempertahankan kebersihan linen dan seragam merupakan hal yang sangat penting diperhatikan untuk mencegah infeksi nosokomial. Kebersihan seragam tenaga kesehatan khususnya perawat termasuk dalam kebersihan lingkungan yang harus diperhatikan karena rentan terkontaminasi oleh cairan tubuh dan debris klien (LeTexier, 2005).

Hasil penelitian terbaru menyatakan $65 \%$ seragam perawat yang merawat klien dengan penyakit Methicillin-Resistant Staphylococcus aureus (MRSA) terkontaminasi dengan kuman MRSA (LeTexier, 2005). Pengelolaan seragam dengan tepat sangat penting mengingat kemungkinan meningkatnya infeksi bakteri yang resisten di mana dapat meningkatkan resiko infeksi pada tenaga kesehatan dan klien. Bakteri gram positif memiliki kemampuan untuk mempertahankan diri di permukaan benda-benda di dalam lingkungan rumah sakit (LeTexier, 2005). Marcus, (1998); menyatakan bahwa pengelolaan seragam atau mengganti pakaian seragam di rumah sakit dapat menurunkan risiko penyebaran patogen dari rumah sakit ke rumah dan sebaliknya.

Penelitian terbaru dilakukan oleh Rumah Sakit Anak Shiriners bekerja sama dengan Departemen Bedah Universitas Cincinnati dalam mengamati daya hidup bakteri Enterococci dan Staphylococci pada bahan linen dan plastik rumah sakit.

Penelitian tersebut menggunakan dua jenis bahan. Bahan pertama $100 \%$ terbuat dari katun (pakaian seragam), sedangkan bahan kedua perpaduan antara $60 \%$ katun dan $40 \%$ poliester (jas lab). Seluruh kuman Staphylococci dapat bertahan hidup setidaknya satu hari pada kedua bahan tersebut. Data dari penelitian ini menyatakan bakteri Enterococci dan Staphylococci dapat bertahan hidup berhari-hari hingga berbulan-bulan setelah tindakan pengeringan bahan yang dilakukan di rumah sakit. Penelitian ini membuktikan bakteri Enterococci dan Staphylococci dapat bertahan hidup dalam jangka waktu lama pada bahan yang umum digunakan oleh klien dan tenaga kesehatan. (LeTexier, 2005).

Penelitian tersebut memberikan gambaran perlu dilakukannya studi yang berhubungan dengan penggunaan seragam klinik di rumah sakit (terutama dikarenakan fenomena tersebut banyak ditemui peneliti di ruangan, baik di rumah sakit besar maupun kecil terutama di daerah yang pernah dikunjungi peneliti). Penelitian ini dibatasi pada lamanya penggunaan seragam klinik dengan peningkatan jumlah mikroorganisme pada seragam saja. Pembatasan ini dilakukan peneliti mengingat keterbatasan dana yang dianggarkan. 
Jurnal Keperawatan Indonesia, Volume 10, No.1, Maret 2006; 5-10

\section{METODE}

Penelitian ini menggunakan desain deskriptif korelatif di mana penelitian akan dibagi menjadi beberapa seri, masing-masing meliputi: 1) uji peningkatan jumlah mikroorganisme menggunakan plat agar (dilakukan dengan pengambilan swap pada seragam klinik sebelum digunakan, setelah digunakan selama satu hari, dan setelah dua hari penggunaan, 2) uji mikrobiologi dengan menghitung peningkatan jumlah koloni mikrooganisme pada plat agar (setelah plat agar diinkubasi dalam inkubator selama 24 jam), 3) identifikasi jenis kuman pada seragam

Populasi pada penelitian ini adalah mahasiswa FIKUI program profesi 2004-2005 yang berdinas di ruang rawat Neurologi di salah satu rumah sakit pemerintah di Jakarta. Penelitian dilakukan dengan mengambil sampel swap seragam klinik mahasiswa profesi di rumah sakit. Observasi dilakukan pada sejumlah 9 sampel swap dari tiga orang responden selama tiga hari. Pemilihan sampel ini dilakukan karena keterbatasan dana yang tersedia. Mahalnya biaya pemeriksaan mikrobiologi untuk perhitungan jumlah koloni mikroorganisme menyebabkan penelitian ini hanya dapat dilakukan pada tiga orang responden.

Pada tahap awal pengumpulan data dilakukan pemilihan sampel dan penjelasan mengenai prosedur penelitian terhadap sampel penelitian. Pada tahap pengumpulan data, swap diambil pada seragam klinik mahasiswa dalam kondisi bersih (sebelum digunakan), setelah hari pertama penggunaan seragam, dan setelah hari kedua penggunaan seragam. Pengambilan sampel dilakukan dengan mempertahankan kesterilan tindakan dan pengantaran sampel melalui media transport dilakukan dengan mempertahankan kestabilan kondisi lingkungan bagi mokroorganisme sehingga tidak terjadi penambahan jumlah kuman dari dunia luar.

\section{Cara Penafsiaran dan Penyimpulan Hasil Penelitian}

Pengumpulan data dilakukan melalui pengambilan swap seragam dilanjutkan dengan penanaman dan inkubasi swap seragam mahasiswa profesi dalam plat agar selama 24 jam. Dari uji plat agar dan uji mikrobiologi tersebut, dihitung peningkatan jumlah koloni plat agar setiap hari. Kemudian hasilnya dibandingkan menggunakan uji ANOVA.
Instrumen observasi:

\begin{tabular}{|c|c|c|c|}
\hline $\begin{array}{c}\text { Penggunaan } \\
\text { Seragam } \\
\text { hari ke-... }\end{array}$ & $\begin{array}{l}\text { Jumlah } \\
\text { Koloni } \\
\text { Sebelum } \\
\text { Seragam } \\
\text { Digunakan } \\
\text { (Kontrol) }\end{array}$ & $\begin{array}{c}\text { Jumlah } \\
\text { Koloni } \\
\text { Setelah } \\
\text { Seragam } \\
\text { Digunakan }\end{array}$ & $\begin{array}{c}\text { Peningkatan } \\
\text { Jumlah } \\
\text { Koloni }\end{array}$ \\
\hline 1 & 0 & 0 & \\
\hline 2 & 0 & 0 & \\
\hline
\end{tabular}

\section{Hasil Penelitian}

Penelitian ini membuktikan dan menjawab pertanyaan penelitian yang diajukan bahwa semakin lama seragam klinik digunakan semakin banyak jumlah mikroorganisme pada seragam tersebut. Dari hasil penelitian didapatkan data terjadi peningkatan jumlah koloni kuman yang terdapat pada baju seragam klinik yang digunakan mahasiswa dalam praktek klinik profesi setiap harinya. Hal ini dapat dilihat dari tabel 1.

Berdasarkan analisis data menggunakan rumus ANOVA didapatkan data beda rata-rata antara jumlah koloni kuman sebelum penggunaan seragam dibandingkan dengan setelah penggunaan seragam hari kedua sebesar 20.6333,3 ( $p$ value 0,012, $\alpha: 0,05,95 \% \mathrm{CI}: 35513,6-5753,05)$. Berdasarkan data tersebut dibuktikan bahwa terjadi peningkatan yang bermakna terhadap jumlah koloni pada penggunaan seragam pada hari kedua dibandingkan dengan jumlah koloni sebelum penggunaan seragam. Hal tersebut dapat dilihat pada tabel 2 .

Tabel 1.

Hasil pemeriksaan peningkatan jumlah koloni kuman sebelum penggunaan seragam, penggunaan seragam hari- 1 , dan penggunaan seragam hari-2, tahun 2005

\begin{tabular}{ccccccc}
\hline Sampel Penggunaan Kontrol & $\begin{array}{c}\text { Setelah } \\
\text { h-1 } \\
\text { I- }\end{array}$ & $\begin{array}{c}\text { Setelah } \\
\text { H-2 }\end{array}$ & $\begin{array}{c}\text { Peningkatan Peningkatan } \\
\text { Jumlah } \\
\text { Koloni } \\
\text { H-1 }\end{array}$ & $\begin{array}{c}\text { Jumlah } \\
\text { Koloni } \\
\text { H-2 }\end{array}$ \\
\hline & A & $1,20 \times 10^{4}$ & $1,27 \times 10^{4}$ & $2,56 \times 10^{4}$ & $0,07 \times 10^{4}$ & $1,29 \times 10^{4}$ \\
\hline B & $8,90 \times 10^{3}$ & $1,76 \times 10^{4}$ & $3,69 \times 10^{4}$ & $8,70 \times 10^{3}$ & $1,93 \times 10^{4}$ \\
\hline C & $1,54 \times 10^{4}$ & $2,57 \times 10^{4}$ & $3,57 \times 10^{4}$ & $1,03 \times 10^{4}$ & $1,00 \times 10^{4}$ \\
\hline
\end{tabular}


Tabel 2

Hasil analisa menggunakan rumus ANOVA dengan perbandingan ganda (multiple comparisons)- Bonferroni, tahun 2005

\begin{tabular}{|c|c|c|c|c|c|}
\hline \multirow[t]{2}{*}{ (I)VAR00002 } & \multirow[t]{2}{*}{ (J)VAR00002 } & \multirow{2}{*}{$\begin{array}{c}\text { Perbedaan } \\
\text { Rata-rata } \\
\text { (I-J) }\end{array}$} & \multirow[t]{2}{*}{$\begin{array}{c}\text { p value } \\
\text { (Kemaknaan) }\end{array}$} & \multicolumn{2}{|c|}{$\begin{array}{l}\text { 95\% Interval } \\
\text { Kepercayaan }\end{array}$} \\
\hline & & & & $\begin{array}{c}\text { Batas } \\
\text { bawah }\end{array}$ & $\begin{array}{c}\text { Batas } \\
\text { atas }\end{array}$ \\
\hline \multirow[t]{2}{*}{1,00} & 2,00 & $-6,566,66667$ &, 591 & $-21446,9496$ & 8313,6163 \\
\hline & 3,00 & $-20633,333$ &, $012^{*} \quad-$ & $-35513,6163$ & $-5753,0504$ \\
\hline \multirow[t]{2}{*}{2,00} & 1,00 & 6566,66667 &, 591 & $-8313,6163$ & 21446,9496 \\
\hline & 3,00 & $-1,4066,667$ & 063 & $-28946,9494$ & 813,6163 \\
\hline \multirow[t]{2}{*}{3,00} & 1,00 & 20633,3333 &, $012 *$ & 5753,0504 & 35513,6163 \\
\hline & 2,00 & 14066,6667 & ,063 & $-813,6163$ & 28946,9494 \\
\hline
\end{tabular}

\section{PEMBAHASAN}

Berdasarkan hasil penelitian didapatkan peningkatan yang bermakna terhadap jumlah koloni kuman pada penggunaan seragam klinik setelah digunakan dua hari dibandingkan dengan jumlah koloni sebelum penggunaan seragam. Pada hasil pemeriksaan jumlah koloni kuman pada seragam responden A terdapat peningkatan sebanyak $1,29 \times 10^{4}$ koloni, pada seragam responden $\mathrm{B}$ ditemukan peningkatan sebanyak $1,93 \times 10^{4}$ koloni, dan pada seragam responden $\mathrm{C}$ ditemukan peningkatan sebanyak $1,00 \times 10^{4}$ koloni setelah dua hari penggunaaan. Hal tersebut akan meningkatkan potensi terjadinya infeksi nosokomial. Penelitian ini sejalan dengan hasil penelitian LeTexier tahun 2005 yang menyatakan $65 \%$ seragam perawat yang merawat klien dengan penyakit methicillin-resistant Staphylococcus aureus (MRSA) terkontaminasi dengan kuman MRSA. Hasil penelitian ini menegaskan penyataan Walker dan Donaldson pada tahun 1993 yang menyatakan seragam perawat merupakan salah satu media dalam terjadinya infeksi nosokomial.

Kebersihan seragam tenaga kesehatan khususnya perawat termasuk dalam kebersihan lingkungan yang harus diperhatikan karena rentan terkontaminasi oleh cairan tubuh dan debris klien (LeTexier, 2005). Berdasarkan hasil diskusi dengan responden penelitian, dua dari tiga $(66,7 \%)$ responden mengatakan bahwa mereka mengganti seragam klinik setiap hari dan satu orang responden $(33,3 \%)$ mengganti seragam klinik dua hari sekali.
Namun peneliti masih melihat adanya fenomena pada mahasiswa di luar responden penelitian yang menggunakan seragam klinik lebih dari dua hari dengan alasan keterbatasan jumlah seragam klinik yang dimiliki (dua pasang seragam) dan jumlah hari dinas yang ganjil sehingga setelah dua hari di awal minggu mereka mengganti baju seragam klinik, kemudian menggunakan seragam klinik baru yang sama pada tiga hari di akhir minggu.

Fenomena penggunaan seragam klinik lebih dari dua hari juga dilakukan oleh para perawat di ruang rawat. Melalui penelitian ini pihak fakultas sebagai penyelenggara praktik pendidikan klinik (profesi) perlu menegaskan dan meningkatkan himbauan kepada mahasiswa untuk meningkatkan pengelolaan seragam kliniknya dengan tidak menggunakan seragam klinik lebih dari dua hari karena telah terbukti berpotensi menunjang terjadinya infeksi nosokomial melalui pertumbuhan koloni kuman pada baju seragam.

Secara umum, mayoritas koloni kuman yang ditemukan adalah bentuk batang berflora (bacillus) yang habitatnya adalah udara dan permukaan area benda termasuk peralatan dan seragam. Kuman dengan bentuk tersebut termasuk dalam kategori kuman gram positif. Hal ini mendukung hasil penelitian LeTexier tahun 2005 yang menyatakan bahwa bakteri gram positif memiliki kemampuan untuk mempertahankan diri di permukaan bendabenda di dalam lingkungan rumah sakit. Hal ini menambah pentingnya tindakan pengelolaan seragam dengan tepat mengingat kemungkinan meningkatnya infeksi bakteri yang resisten dimana dapat meningkatkan risiko infeksi pada tenaga kesehatan dan klien.

\section{KESIMPULAN}

Penelitian ini membuktikan dan menjawab pertanyaan penelitian yang diajukan bahwa semakin lama seragam klinik digunakan semakin banyak jumlah mikroorganisme pada seragam tersebut. Dari hasil penelitian didapatkan data terjadi peningkatan yang bermakna terhadap jumlah koloni pada penggunaan seragam pada hari kedua dibandingkan dengan jumlah koloni sebelum penggunaan seragam dengan beda ratarata antara jumlah koloni kuman sebelum penggunaan 
Jurnal Keperawatan Indonesia, Volume 10, No.1, Maret 2006; 5-10

seragam dibandingkan dengan setelah penggunaan seragam hari kedua sebesar 20.6333,3 ( $p$ value 0,012 , $\alpha: 0,05,95 \%$ CI: 35513,6-5753,05). Adapun mayoritas koloni kuman yang ditemukan adalah bentuk batang berflora (bacillus) yang merupakan bentuk koloni kuman gram positif yang memiliki kemampuan untuk mempertahankan diri dalam jangka waktu yang relative lama di permukaan benda-benda di dalam lingkungan rumah sakit termasuk pada seragam klinik. Hal ini menekankan pentingnya pengelolaan penggunaan seragam klinik dengan tepat yaitu tidak lebih dari dua hari.

Institusi pendidikan keperawatan sebaiknya lebih menekankan pentingnya pengelolaan seragam klinik mahasiswanya melalui kebijakan yang lebih tegas dengan menekankan agar mahasiswa tidak menggunakan seragam kliniknya pada hari berikutnya (hanya satu kali pakai). Walaupun pada hasil penelitian ini adanya peningkatan jumlah kuman yang signifikan ditemukan setelah penggunaan hari kedua. Seragam yang telah digunakan sebaiknya tidak digunakan sampai di rumah (pulang ke rumah tidak menggunakan seragam klinik). Pihak manajerial rumah sakit dianjurkan untuk menekankan kepada para perawat untuk tidak menggantung seragam yang telah dipakai yang biasanya akan digunakan kembali. Perawat diharapkan dapat mengganti seragam dinas setiap hari.

Penelitian ini merupakan salah satu dasar untuk penelitian berikutnya antara lain penelitian mengenai jenis dan proporsi kuman yang terdapat pada seragam, kemampuan kuman untuk dapat bertahan hidup, dan penelitian lainnya. Hal ini mengingat masih terbatasnya penelitian mengenai infeksi nosokomial terkait dengan pengelolaan linen dan seragam (EN).

\section{* Dana Peneliti Muda V FIK-UI, 2005}

* Hanny Handiyani, S.Kp., M.Kep. : Staf Akademik Dasar Keperawatan dan Keperawatan Dasar FIK UI

** Ns. Yasephin Megapurwara, S.Kep. : Staf Akademik Dasar Keperawatan dan Keperawatan Dasar FIK UI

\section{KEPUSTAKAAN}

Dring S (1987) Uniform views. Nursing Times, 83, 25,19

Janet, M.C. (1998). Report hospital-acquired infection. Nursing standard. Volume 13 (3), October 7-13, 1998, 33-35

Kozier, B., Erb, G. \& Oliveri, R. (1995). Fundamentals of nursing: Concepts, process \& practice. (Edisi 4). California: Addison-Wesley Publishing Co.

LeTexier, Ruth. (2005). Coming clean on home laundered scrubs. Infection Control Today: The voice of authority in infection control. May, 2005 (www.infectioncontroltoday.com)

Marcus, L and Marcus, E.(1998). Nosocomial Zoonoses. The New England Journal of Medicine. Volume 338:757-759, March 12, 1998

Parker, M.J (1978). Microbiology for nurses. $\left(5^{\text {th }}\right.$ ed). London: Bailliere Tindall

Potter \& Perry. (2001). Fundamentals of nursing. London: Harcourt Publishers International

Pritchard, A.P., Mallett.J. (ed). (1992). Manual of clinical nursing procedures. (3th ed). Cambridge: The University Press

Smeltzer.Sc., Bare B.G. (1996). Brunner \& Suddarth's textbook of medical surgical nursing. ( $8^{\text {th }}$ ed). Philadelphia: Lippincott Raven Publishers 